\title{
Effects of winter on genetic structure of a natural population of Drosophila melanogaster
}

\author{
C. BIÉMONT \\ Biologie des Populations, Université Lyon 1, F 69622 Villeurbanne
}

\begin{abstract}
Summary
A natural population of Drosophila melanogaster from a cellar was followed throughout the year and its genetic structure analysed by a sib-mating approach (based on distributions of viability ratio in sib-mating offspring) and enzymatic polymorphism. Flies found early in spring, that had resisted cold temperature and food shortage during winter, were free of deleterious factors; no inbreeding depression was observed in the viability of their immediate descendants. In contrast, a population established during winter in a bucket of ripe fruit placed in the cellar, showed a high frequency of lethals. In both cases, the increasing effective size that followed the return of a favorable environment was associated with an inbreeding depression in further generations. The collected flies were highly heterozygous at enzyme loci, although the pattern was perturbed by drift and sampling error.

The genetic structure of the populations may thus depend not only on effective population size but also on selection favoring heterozygotes either free of or bearing lethals (according to the conditions encountered). The observation of an annual cycle of change in enzymatic and deleterious allele frequencies, and degree of heterozygosity, depends then on when and how flies are collected.
\end{abstract}

Key words : Natural population, genetical structure, inbreeding, natural selection, D. melanogaster.

\section{Résumé}

\section{Effets de l'hiver sur la structure génétique d'une population naturelle de Drosophila melanogaster}

Une population naturelle de Drosophila melanogaster d'une cave fut suivie tout au long d'une année. Sa structure génétique fut approchée par l'analyse de la viabilité après croisements frère-sœur (une mesure du "fardeau génétique ») et le polymorphisme enzymatique. Les mouches de printemps qui avaient résisté à l'hiver, n'avaient pas de gènes létaux. La fréquence de ces gènes augmentait cependant rapidement avec l'effectif de la population pour atteindre une valeur d'équilibre dans les populations d'été et d'automne. Par contre, la fréquence des gènes létaux était forte dans une population maintenue pendant l'hiver sur des fruits placés dans la cave. On conclut que la structure génétique de ces populations doit dépendre non seulement de leur taille effective mais aussi de la sélection 
naturelle favorisant les individus hétérozygotes pour les loci enzymatiques; ces individus portaient ou ne portaient pas de gènes létaux selon l'environnement auquel était soumise la population. L'observation d'un cycle annuel de variation de fréquence des gènes enzymatiques et délétères, ainsi que du degré d'hétérozygotie, doit alors dépendre du moment et de la manière dont les mouches sont collectées.

Mots clés : Population naturelle, structure génétique, consanguinité, sélection naturelle, D. melanogaster.

\section{Introduction}

The role of selection for heterozygotes in maintaining the genetic variability of populations is one of genetic's most intriguing problems. Though some works suggest that highly heterozygous individuals enjoy an enhanced developmental homeostasis, which enable them to adjust their development and physiological processes in response to environmental challenge (LERNER, 1954), the mechanisms which determine a population's genetic structure remain obscure (see LEWONTIN, 1974, for a review). One of the theories to emerge from observations on genetic variability in populations of Drosophila is the proposal that extreme environmental conditions favor heterozygous individuals (see PARsons, 1983, for a review). But it is not clear whether these heterozygotes harbor lethal alleles (GolubovsKY, 1970 ; LEWONTIN, 1974) or are free of lethals (Band, 1963 ; Band \& Yves, 1961, 1968 ; Hiraizumi \& Crow, 1960 ; MukaI \& Yamaguchi, 1974).

The deleterious gene frequencies in natural populations can fluctuate in response to environmental events which affect population size. The same environmental events can select for or against heterozygous individuals and may or may not be followed by inbreeding depression. Hence, the proposal that Drosophila melanogaster demonstrates cyclic changes in deleterious gene frequencies due to various and extreme climatic conditions encountered every year, largely depends on spatial and temporal structure of the population. For instance, selection for heterozygotes free of lethals might be observed only if the flies were caught just before the effective size of the population expands and becomes large enough for lethals to accumulate.

An important point is that the genetic techniques most often used to compare the homozygous and heterozygous effects of deleterious genes or gene complexes involve making chromosomes totally homozygous (LEwONTIN, 1974). However, it has been shown recently that certain mutations and lethals observed in natural populations are the result of interactions between the wild strain studied and the marker strain used (KIDWELL, 1983 ; BREgliano et al., 1980). Note also that the general method of producing homozygous chromosomes is an inbred mating system (generally between brothers and sisters), so that, in addition to the chromosomes being studied, the entire genome is rendered more homozygous (LEwontin, 1974). As a result one cannot distinguish the effects of homozygosity of a particular chromosome from a general increase in homozygosity of the background genotype. In order to eliminate this problem, a different approach has been adopted. The approach involves studying the distribution of viability of offspring of sib matings (BIÉMONT, 1983; Bı́́MONT \& BouClier, 1983).

This paper reports the results of sib-mating analysis in association with a survey of enzymatic polymorphism of a cellar population of Drosophila melanogaster. The 
study concerns the population's genetic makeup in winter, during which harsh environmental conditions severely reduced the population size, and in early spring where a few flies may survive to found a new population.

\section{Material and methods}

\section{A. Collection site}

Flies were collected from a cellar in Valence (Drome, France). The cellar measured 4 by 4 meters with a dirt floor. Migrant flies apparently may enter and leave via a small window. Though many different kinds of fruit are stored in this cellar through the year, no fruit remained available during the winter period from December to the beginning of June when the first fruit appears. Initial collection trips to the vacant cellar, from December 1981 through the following April, were unrewarding. It was not until early May 1982 that 2 Drosophila melanogaster females were first captured. They were found to have been fertilized prior to capture so that their brother and sister offspring were analysed for viability (fraction of the fertilized eggs which develops to the adult stage). The progeny of one of these wild females, arbitrarily chosen, was maintained in the laboratory so that the genetic structure of her non overlapping descendant generations could be analysed. This population is identified as the "isofemale population». In June, cherries and strawberries were stored in the cellar and a Drosophila population expanded rapidly. In each of June, September and October, a sample of about 50 females was taken from the cellar and laboratory populations established from their offspring. The $F_{2}$ of these females were first analysed in order to avoid possible influence of the environment under which the mothers had undergone development. The established populations were then analysed again a few generations later.

In November 1982, at a time where the flies usually disappear, an experimental « natural » population was set up by putting some ripe apples and pears in a bucket inside the cellar. The population of Drosophila which established in the bucket was undisturbed for 4 months. The minimum temperature of the cellar during this period was $10^{\circ} \mathrm{C}$; the temperature inside the bucket was not determined. A sample of the population was taken in February 1983 and the $F_{2}$ flies analysed. Also, a « February " population was established in the laboratory (from about 50 females) and maintained in bottles by tipping over large number of parents in each generation. The flies were reared in the laboratory on a standard axenic-dried yeast-agar medium at $25^{\circ} \mathrm{C}$ in the dark.

\section{B. The sib-mating analysis}

Genetic variability in species that lack genetic markers, is classically evaluated by comparing effects of various inbred crosses on average viability. This method assumes a linear relationship between the intensity of inbreeding depression and the theoretical value of the inbreeding coefficient. The assumptions made in this model are not always met, and their biological meanings have been largely debated and 
criticized (see for example Lewontin, 1974). The following approach involves studying the distributions of viability values of sib-mating offspring. This method can then be used in species that lack adequate genetic markers and it is free of biological assumptions about the nature of lethality.

For all the populations, 50 males and 50 females were chosen at random from either the $F_{2}$ offspring or the established laboratory populations. The flies were then crossed in pairs. The pairs so formed were set up and allowed to lay eggs. 50 eggs laid by each mated female were transferred to a vial with fresh medium to allow $F_{1}$ progeny to develop. The $F_{1}$ adults emerging from the eggs were counted. Egg viability for each pair of these controls was then estimated by calculating the percentage of fertilized eggs that produced adults. At hatching time, one brother-sister $F_{1}$ pair for each progeny group was separated and allowed to mate. The eggs laid during 2 successive periods of $10 \mathrm{~h}$ each, were collected. Replicate samples of 50 eggs from each lot were then transferred to new vials where $F_{2}$ progeny developed. The $F_{2}$ adults emerging from each replicate lot were counted and viability ratios were determined. The data from replicates, found to be homogeneous by chi-square tests, were pooled. These data lead thus to viability distribution curves for control and sib generations.

Note that the first descendant of each of the wild female collected in May are all sibs. The offspring viability was analysed on about 50 brother-sister pairs for each progeny.

\section{Electrophoresis}

A sample of 50 males from each population and some laboratory generations was analysed by standard horizontal starch gel electrophoresis. The loci were run on a tris-citrate buffer system (PoulıK, 1957) and stain on the same gel. Five enzymatic loci were examined : alcohol dehydrogenase ( $\mathrm{Adh}$ ), alpha-glycerophosphate dehydrogenase $(\alpha-\mathrm{Gpdh})$, Esterase-6 (Est-6), Esterase-C (Est-C) and phosphoglucomutase (PGM). The staining methods were those of GIRARD (1976).

\section{Numerical analysis}

\section{Distributions of viability values}

The distributions of viability values were analysed globally by a correspondence factorial analysis (BENZECRI, 1973). This method of ordination allows depiction of the different populations that are characterized by the pattern of distribution of their viability values. Each population is defined by its position in a space of as many dimensions as the number of classes of viability values. Distances between 2 populations are then measured by a chi-square metric. The aim of the analysis is to find the maximum variability axes of the variance-covariance matrix. Hence, the graph distance between any 2 populations is a measure of their similarity for viability distribution. This factorial analysis takes account of all the information contained in the distribution curves. It is then much more powerful in determining differences between populations than a viability index based on average values. 
Electrophoresis data

Using the allelic frequency data, the within-population fixation index $\left(\mathrm{F}_{\text {IS }}\right)$ was calculated

$$
\mathrm{F}_{\mathrm{IS}}=1-\frac{\mathrm{H}_{\mathbf{o}}}{\mathrm{H}_{\mathrm{C}}}
$$

for each polymorphic enzyme locus, where $\mathrm{H}_{\mathrm{O}}$ is the observed proportion of heterozygotes and $\mathrm{H}_{\mathrm{C}}$ is the expected Hardy-Weinberg proportion. A positive value of $F_{\text {IS }}$ indicates an excess of homozygotes. $\bar{F}_{I S}$, the mean fixation index for a population over all loci, represents the average deviation of the population's genotypic proportions from the Hardy-Weinberg equilibrium due to the combined effects of finite population size, selection, inbreeding, and other forces affecting the genetic makeup of the population.

To test whether the values of $F_{\text {IS }}$ represent significant deviations from panmixia, a one-tailed chi-square test was used according to the formula of Li \& Horvitz (1953).

$\chi^{2}=\mathrm{F}_{\mathrm{IS}}^{2} \mathrm{~N}_{\mathrm{i}}(\mathrm{k}-1)$ with $\mathrm{k}(\mathrm{k}-1) / 2$ degrees of freedom, with $\mathrm{N}_{\mathrm{i}}$, sample size and $\mathrm{k}$, number of alleles. Since this $\chi^{2}$ is the same as the one calculated directly from the observed and expected genotypic frequencies, $\bar{F}_{\mathrm{IS}}$ was tested for significance by a summation of all the individuals $\chi^{2}$ associated with each locus. The re-

sulting $\chi^{2}$ has then $\sum_{i=1}^{m} k_{i}\left(k_{i}-1\right) / 2$ degrees of freedom, with $m$, number of loci in the population.

\section{Results}

\section{A. Distributions of viability values}

The distributions of the viability ratios are shown in figures 1 and 2 . In general the curves appear heterogeneous in that we can distinguish 2 groups of pairs : those with high viability values equal or above 0.90 and those with viability values less than 0.90 . It can be easily seen that the brother-sister crosses produced consistently a smaller proportion of viable offspring than did control crosses. These sib matings result also in a wide scatter of viability values leading thus to a trend towards low values. These distribution patterns reflect the expression of deleterious factors due to the increased homozygosity of the genome in the offspring from the sib pairs (LEwONTIN, 1974 ; BIÉMONT, 1983). Thus, the comparison of populations and generations on the basis of the distributions of the viability ratios reflect the amount of deleterious factors those populations concealed. For such comparison, the distributions were analysed by a correspondence factorial analysis (BENZECRI, 1973). Graphical representation of the results of this statistical analysis is shown in figure 3.

The analysis separates the controls from the sib-matings as a function of the proportion of high viability batches. The wide scatter of the sib-mating progenies on the left part of the plane results from their trends towards low viability values. 


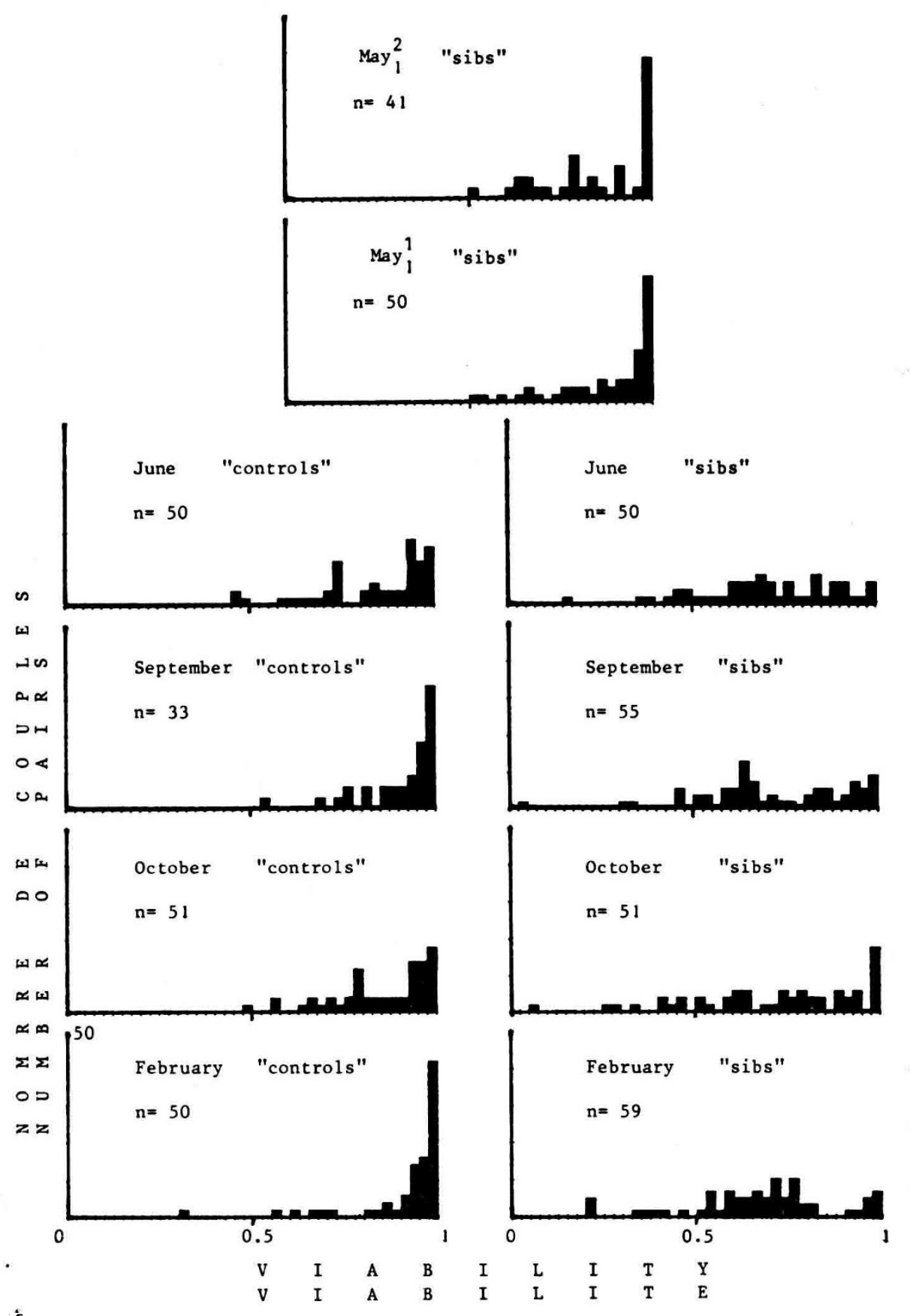

FIG. 1

Distributions of viability values, in progeny from unrelated and sibling crosses of natural populations of $\mathrm{D}$. melanogaster.

Distributions des valeurs de la viabilité (nombre d'adultes/nombre d'aufs fécondés) de descendances d'individus appariés frères-sauturs (sibs) ou non apparentés ( controls»), dans des populations naturelles de $\mathrm{D}$. melanogaster.

n : Number of pairs.

Nombre de couples étudiés.

Ordinate : number of pairs in each viability class.

En ordonnées: nombre de couples dans chaque classe de viabilité. 

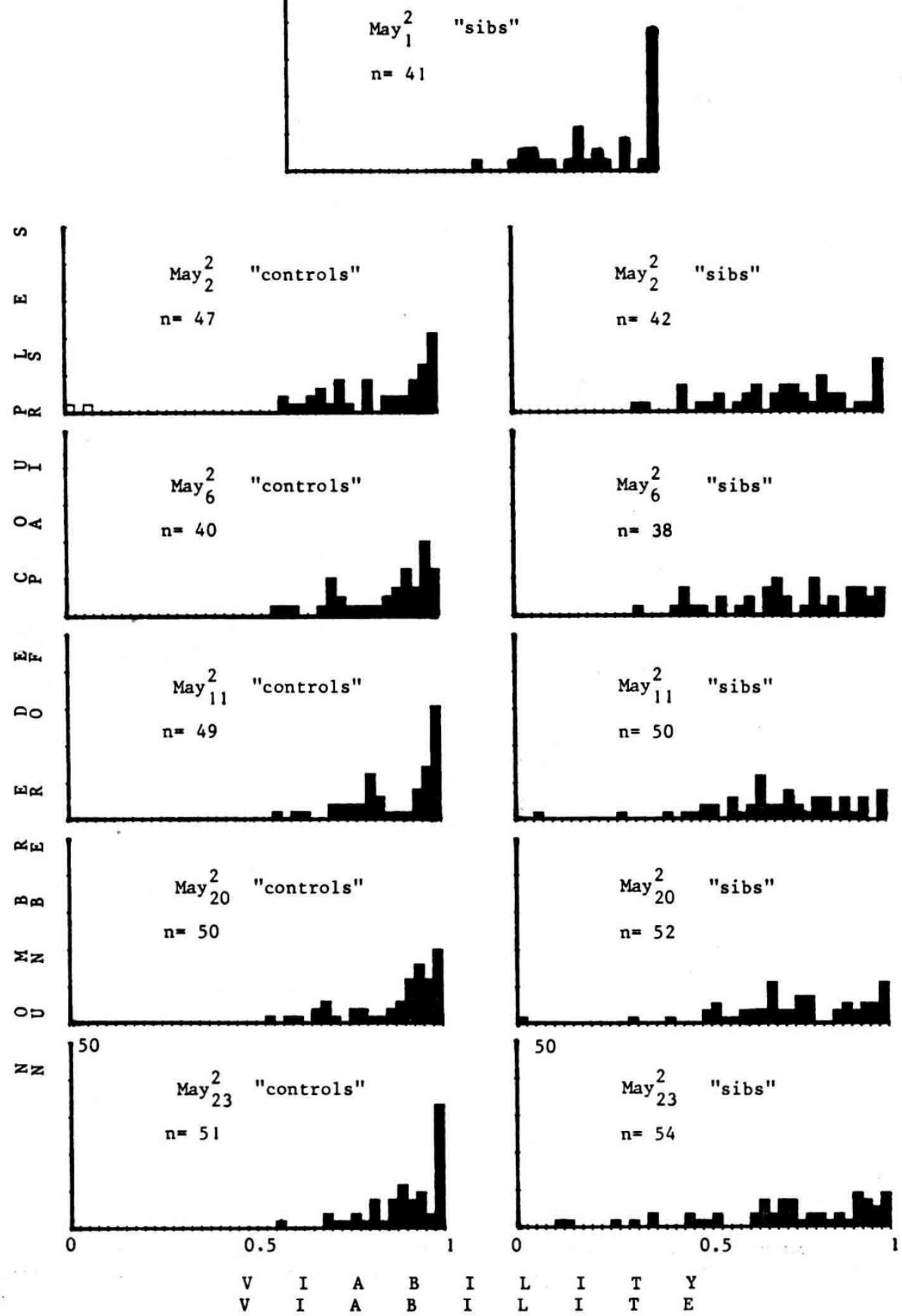

FIG. 2

Distributions of viability values, in progeny from unrelated and sibling crosses in generations descending from one $\mathrm{D}$. melanogaster female captured in May. The inferior indice indicates the number of the laboratory generation on which the viability analysis was done.

Distributions des valeurs de la viabilité dans des descendances d'individus frères-saurs (《sibs》) ou non apparentés ( controls》)

pour des générations dérivées d'une femelle de D. melanogaster capturée en mai. L'indice inférieur indique le numéro de la génération de laboratoire sur laquelle

n : Number of pairs. le test de viabilité fut cffectué.

Nombre de couples étudiés.

Ordinate : number of pairs in each viability class.

En ordonnées : nombre de couples dans chaque classe de viabilité. 


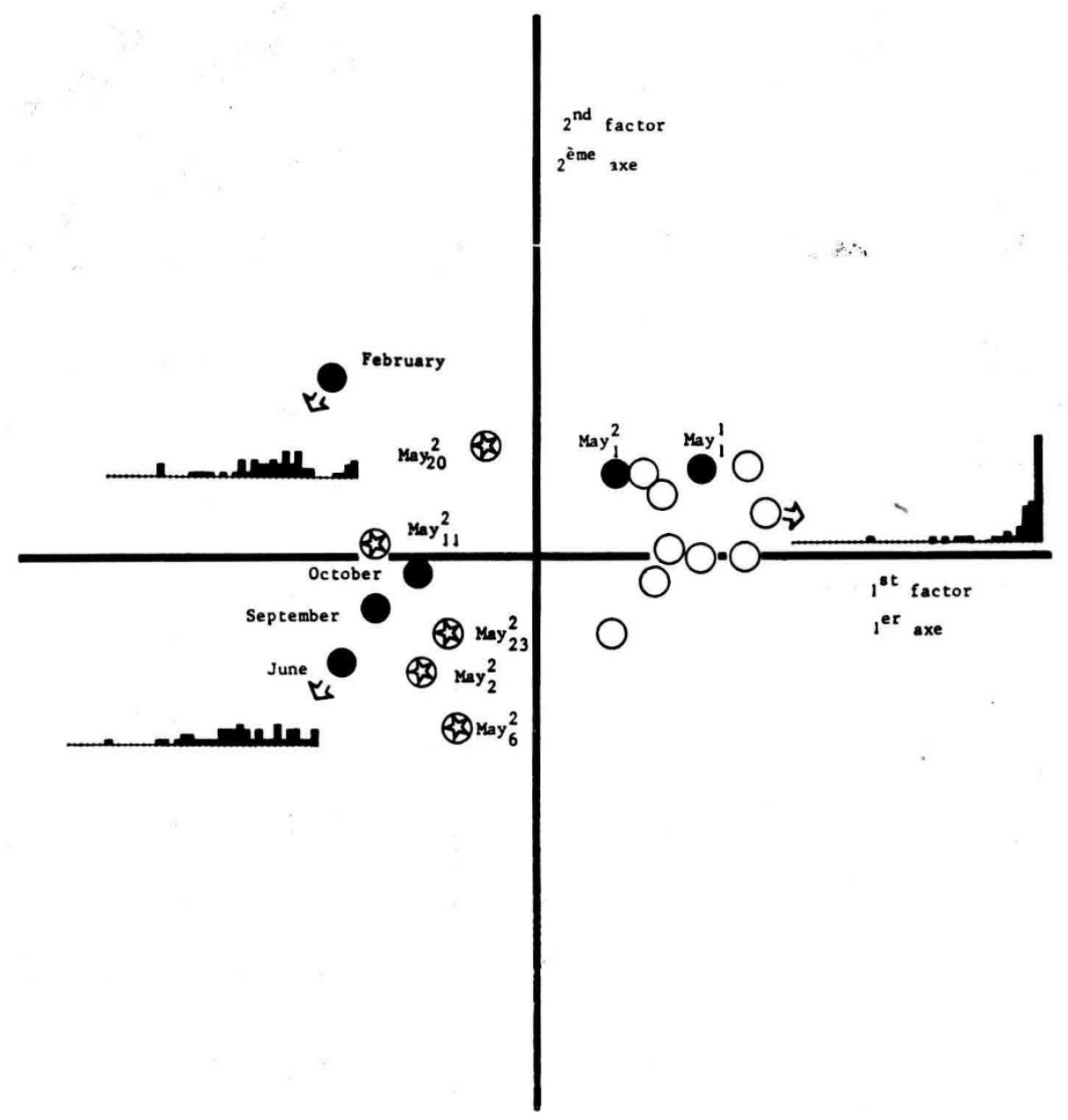

FIG. 3

Correspondence analysis of distributions of viability values of progeny from unrelated or sibling matings of $\mathrm{D}$. melanogaster from natural and laboratory populations.

The horizontal and vertical axes correspond respectively to the first and second principal components.

o crosses between unrelated flies (controls)

- sib-mating tests in the natural populations

(2) sib-mating tests in the laboratory generations of the isofemale population descending from the offspring of the female collected in May.

Analyse des correspondances des distributions des valeurs de viabilité des descendances de couples frères-scours ou non apparentés, pour les populations naturelles et celles de laboratoire.

Les axes horizontaux et verticaux correspondent au ler et au $2^{\text {nd }}$ facteurs de l'analyse respectivement.

- croisements entre individus non apparentés (témoins)

- croisements frère-scour: populations naturelles

(2) croisements frère-saur : générations de laboratoire de la population "isofemelle * descendant d'une femelle capturée en mai. 
This is particularly evident for the February and June populations that are positioned on the 2 nd axis of the analysis according to the average value of the low viability classes.

The main striking result, however, is the occurrence of the May sib offspring (May $_{1}{ }_{1}$ and $\mathrm{May}_{1}^{2}$, figure 3 ) among the controls. Since the offspring of each wild May female were sibs, we indeed expected the distributions to be typical of the other sib matings. The fact that these 2 distributions resemble those of the controls suggests that there was a low number of masked deleterious factors in these offspring. Therefore, the flies captured in May that have survived the harsh conditions of winter are characterized by a low frequency of concealed deleterious factors. We can of course wonder if such results could not be due to multiple inseminations of the females. This could lead to a lower coefficient of kindship of the offspring. A distribution of viability ratios intermediate between the controls and the other sib generations should then be observed. This is not consistent with the observation that the shape of the distributions of viability of the 2 May female progenies falls within the range of the controls.

Another interesting result is the inbreeding depression shown by the isofemale population established from one of the females captured in May (May, figure 3). This inbreeding depression, revealed by sib matings, is seen from the second generation in the laboratory on (May.2.

\section{B. Allozyme assay}

The allozyme frequencies for all the populations and laboratory generations are reported in table 1. Some populations appear monomorphic for Adh, Est-C or PGM, loci with low degrees of polymorphism; so, sampling error may well explain this fact. Unfortunately, the May collected female, that we chose to establish the isofemale population followed for many generations (May in tables 1 and 2), was monomorphic for Adh, Est-C and $\left(x-G\right.$ pdh. The non significant values of $F_{\text {Is }}$ for $\mathrm{May}_{1}^{\prime}$ and of $\mathrm{F}_{\mathrm{Is}}$ for PGM in $\mathrm{May}_{1}^{2}$ (tabl. 2) lead us to reject an explanation in terms of inbreeding, since in such a case, all loci should show an excess in homozygosity. However, the individual values of $F_{I s}$ for Esi-6 are high in the May' sibs (May ${ }_{1}^{2}$ in table 2) and also in February $\left(\right.$ Feb $\left._{10}\right)$, June (Jun.) and October (Oct.) populations. This is consistent with the observations made by GILBERT \& RICHMOND (1982) who reported that cage populations have an overall significant deficit of heterozygotes at the Est-6 locus. This was interpreted as reflecting nonrandom mating with respect to the Est- 6 locus. In the isofemale May² population settled in the laboratory, one can note an increasing Est- $6^{S}$ allele frequency with the generation number. A similar tendency scems also to exist for the PGM locus but the PGMS allele frequency reached at the $23^{r \cdot 1}$ generation (May:- is higher than what is observed in the other populations. It appears that the May2 isofemale population maintained a high overall degree of heterozygosity in spite of the 3 monomorphic enzyme loci. Note that for the May sibs the degree of heterozygosity is similar to that of the other natural populations (tabl. 2).

The survey did not reveal the summer-to-autumn increase in frequency of the $\alpha-\mathrm{ppdh}^{\mathrm{S}}$ allele observed in other studies (BERGER, 1971 ; DAVID, 1982). In addition, 


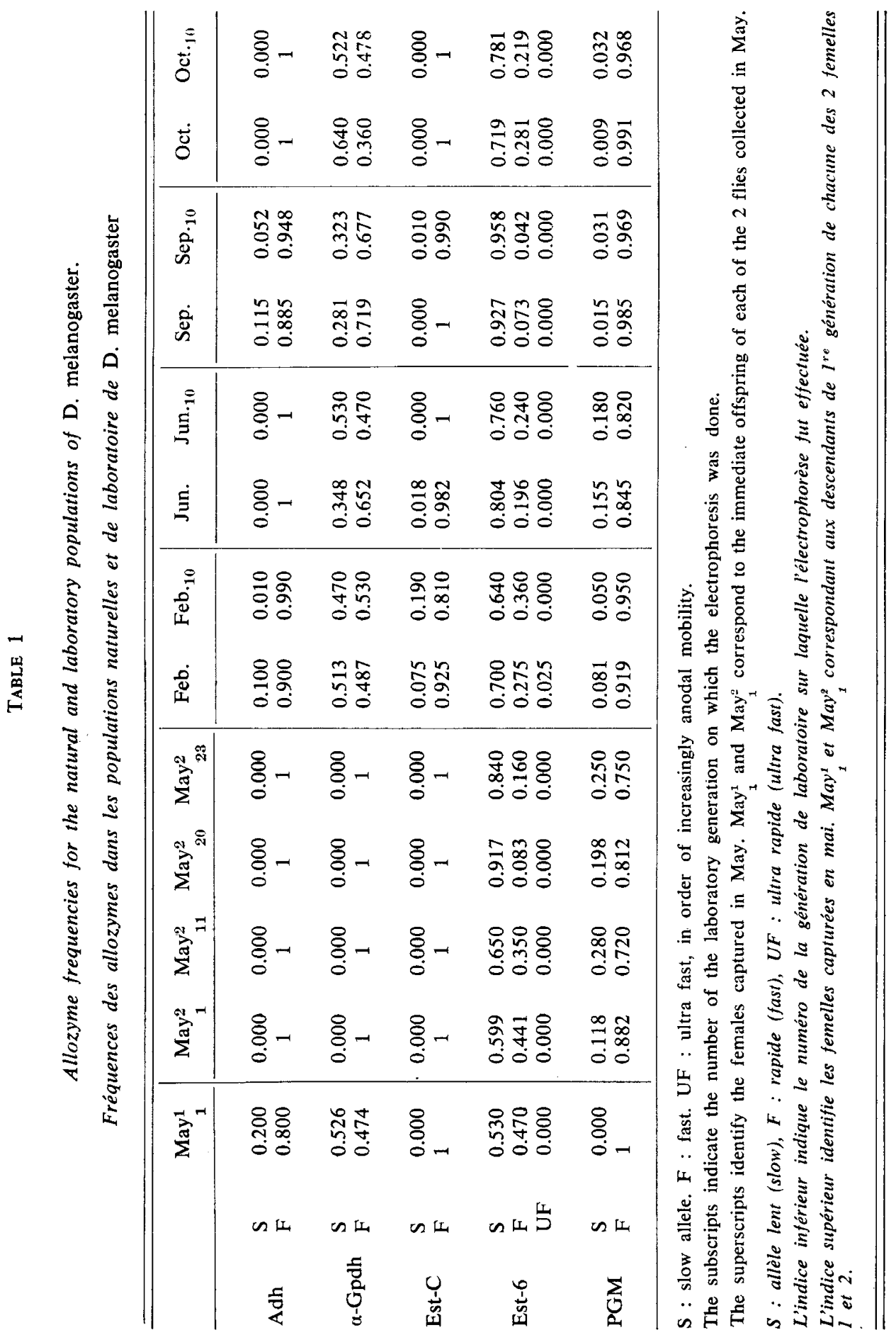




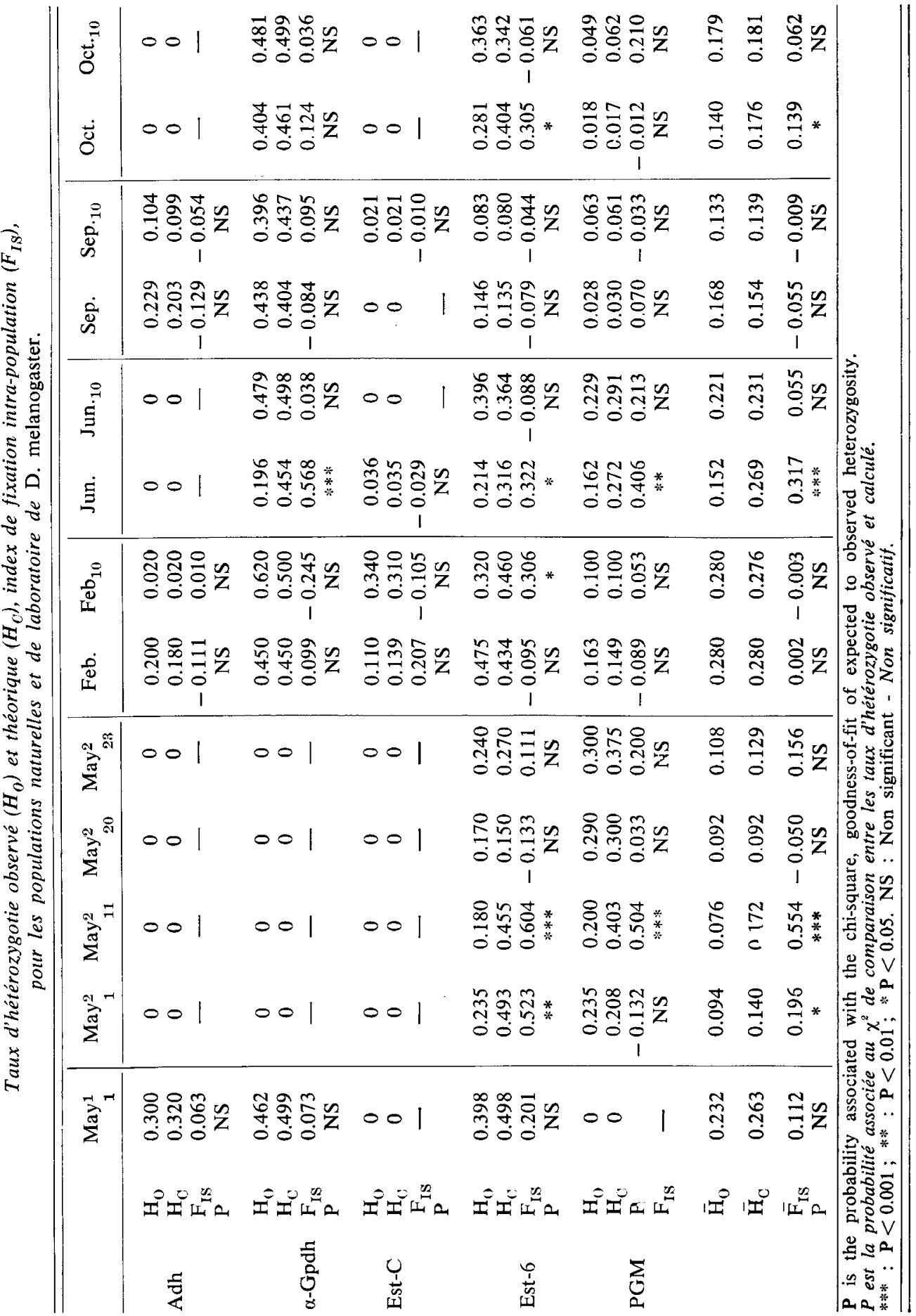


though heterogeneity existed among the natural populations, as in the DAvID's (1982) survey, frequencies are similar for many polymorphic loci between natural and laboratory populations as reported by BERGER (1971).

Though the effective size of the population present in May in the cellar was small, the $F_{\text {Is }}$ values and degree of heterozygosity of the descendants of the 2 flies captured (tabl. 2) suggest that these flies were not inbred. Indeed, except for the Est- 6 locus, the $F_{\text {Is }}$ values are small and not significant. However, this picture changed after some generations in the laboratory : the $F_{\text {Is }}$ values for Est- 6 and PGM (the 2 polymorphic loci) were high and statistically significant at the $11^{\text {th }}$ generation (tabl. 2) reflecting thus a high degree of inbreeding. A similar departure from Hardy-Weinberg equilibrium is also apparent in the June sample (tabl. 2) : $F_{\text {Is }}$ values are high for 3 of the 4 polymorphic loci. The fact that Est-C did not share this effect may be due to sampling error since the frequency of the Est-CS allele is low in this population. However, this departure from Hardy-Weinberg equilibrium disappears completely after 10 generations in the laboratory $\left(\widetilde{F}_{I S}=0.055\right)$. This indicates that the flies caught in June were highly inbred, as expected in a population founded by a few flies. Unfortunately, no estimate of the effective size of this natural population was available.

\section{Discussion}

One problem with the data is that only 2 females were collected at the end of winter in the cellar. However, no fly was expected to be found in the cellar at that time of the year. So, though these fertilized females may not exactly represent a post winter Drosophila population, it is reasonable to say that their genetic makeups, characterized by absence of hidden deleterious alleles, were adequate to survive the winter conditions. Furthermore their genetic structures were exactly what was expected from recent observations on the genetic heterogeneity in natural populations (BIÉmont, 1983 ; BIÉmont \& Bouclier, 1983). Indeed, it was reported that individuals with no lethal alleles were highly heterozygous for enzymatic loci and highly homeostatic (as measured by fluctuating asymmetry for wing length : variance of the difference in score between left and right sides); such flies might thus be favoured under harsh environmental conditions.

As stated by Levins (1968), species which are faced with a variable and unpredictable environment must undergo genetic changes in order to adapt to such conditions. During the year in temperate countries, successive generations are faced with significant variations in temperature and food resources. Therefore, cyclical variations in genetic structure are to be expected. Such periodical seasonal variations have been demonstrated for chromosomal inversion frequencies (DuBININ \& TINIAKov, 1946 ; DoBZhansky, 1970 ; Dobzhansky \& Ayala, 1973), allozyme frequencies (Pasteur, 1974 ; SteINer, 1979), a quantitative trait (Prevosti, 1955) and frequencies of lethal and semi-lethal alleles (Minamori \& SAIto, 1964 ; Golubovsky, 1970 ; Oshima et al., 1971). However, other studies failed to show any significant seasonal variation for either allozyme or inversion (LANGley et al., 1977 ; CAVEner \& Clegg, 1981) or deleterious genes (SPERLICH et al., 1963 ; MiNAMORI et al., 1973). The divergence in results may be due partially to failure to consider adequately the spatial and temporal structures of the studied population; the makeup of the gene pool can be affected 
by total population size, migration rates between populations, mutations rates, average effects of allelic substitutions and varying selection coefficients. Thus, it is difficult to ascertain the causes of fluctuation in gene frequencies.

Our February and May populations may reflect the 2 modes of selection for heterozygotes free of, or bearing lethals mentioned above. The May females demonstrate selection for heterozygous individuals free of lethal alleles. Indeed, the isofemale populations exhibit no decreased progeny viability of the first generation even though the crosses were between brothers and sisters. Thereafter, the rapid expansion of the size of the laboratory population avoids subsequent inbreeding depression that should have been observed due to the deleterious genes that had accumulated rapidly as revealed by the decrease on viability shown by the sib tests (see figure 1). This accumulation of lethals could have been favoured by the lack of lethals in the gene pool of flies selected during winter. This agrees with SPERLICH \& KARLIK (1970) who showed that lethal alleles accumulate rapidly in populations having initially a low frequency of lethals, especially if the population increases rapidly in size. SvED (1973), also found that viability rose sharply in homozygous lines previously choosen for their low viability. Such marked changes were accounted for by postulating that mutations had occurred at very high rate.

The data on the isofemale populations are in agreement with TEMPLETon's report (1980) that results of a founder flush event are not comparable to those associated with the continual inbreeding due to a small population size. Indeed, it is theoretically and experimentally verified that considerable genetic variation is lost in small population because the prolonged inbreeding leads to an increase in homozygosity. However, this is not evident in the experimental "natural » February population. This population is characterized by a high degree of heterozygosity with no departure from Hardy-Weinberg equilibrium and a huge amount of concealed deleterious factors, though this population would have had a small effective size. A similar high degree of heterozygosity was reported in populations of Wool \& SvERDLov (1976). These authors concluded that inbreeding in a small population may eliminate the worst homozygous combinations of genes thus leading to an average gene pool more heterogeneous than expected. Such a selection process associated with inbreeding was also reported as influencing the mean of morphological characteristics from the first generation of inbreeding on (BOUCLIER \& BIÉMONT, 1982). One explanation of the above results is cold-dependent selection in favour of heterozygotes bearing lethals. The selection coefficients might be high enough as to largely compensate for the elimination of lethal alleles by the increasing homozygosity due to the small effective population size.

A high frequency of deleterious alleles also could be mediated by a mutator that, according to BERG (1981), can be selected by a global environmental change. This is particularly relevant since it has been postulated recently that such mutators are associated with inbreeding (BıÉMONT, 1980 ; BIÉMONT and GAUTIER, 1983). This is then consonant with the old observation of ZuITIN (1938) who reported that in Drosophila a change of thermal conditions is capable of producing mutational variations.

In populations maintained in small size, drift and selection associated with inbreeding are expected to be the principal causes of the modification of their genetic structure. Instead, under harsh environmental conditions, in which a few flies manage to survive but a population does not establish, heterozygous individuals free of dele- 
terious alleles are selected. When the conditions become favorable again, the new population formed does not encounter inbreeding depression on viability. However, as the effective size of the population increases, its genetic variability is quickly restored as demonstrated by the rapid accumulation of lethal alleles (SPERLICH \& KARLIK, 1970). These results are consistent with those which previously have shown that adverse environmental conditions in nature might initiate selection against lethal heterozygotes (BAND \& IVES, 1961, 1968; BAND, 1963). If the effects of climatic factors were not so evident in other studies (WATANABE et al., 1976), it may be because mutations, increasing population size, or mixture of local subpopulations have obscured the selection pattern.

In the June, September and October samples, the variation in genetic structure may reflect fluctuation in population size, active migration, and the mixture of different populations following the introduction in the cellar of successive kinds of fruit throughout the season. All these populations harboured large amount of deleterious alleles and showed high and similar degrees of heterozygosity in spite of single locus change. We can thus conclude that in summer and autumn populations that originated either from a mixture of different sub populations that could have resisted winter (for example, populations similar to the cold-submitted February population) or from a few selected flies (the May females), no great fluctuation should be observed in either deleterious allele or enzymatic locus heterozygosities. Migration and effective size variation are the main events in shaping the genetic makeup of such populations.

Received January 4, 1984. Accepted August 23, 1984.

\section{Acknowledgements}

I thank, R. Allemand, J.P. Carante, J. David, M. Klat, J.M. Legay, C. Lemaitre and D. PonTIER for their criticisms on this manuscript, P. FouILlet for computer help and O. Terrier for technical assistance. This work was supported by Centre National de la Recherche Scientifique (laboratoire associé $n^{\circ} 243$ ).

\section{References}

Band H.T., 1963. Genetic structure of populations. Evolution, 17, 307-319.

Band H.T., Yves P.T., 1961. Correlated changes in environment and lethal frequency in a natural population of Drosophila melanogaster. Proc. Natl. Acad. Sci., U.S.A., 47, $180-185$.

Band H.T., Ives P.T., 1968. Genetic structure of populations. IV. - Summer environmental variables and lethal and semilethal frequencies in a natural population of Drosophila melanogaster. Evolution, 22, 633-641.

Benzecri J.P., 1973. L'analyse des données. II. - L'analyse des correspondances, 619 pp., Dunot, Paris.

Berg R.L., 1981. Mutation rates in mutant and non-mutant Drosophila and their bearing on mutability changes in local populations. 50th annual meeting of Society America and Canada, 97, 10 (suppl.).

BERgER E.M., 1971. A temporal survey of allelic variation in natural and laboratory populations of Drosophila melanogaster. Genetics, 67, 121-136. 
BıÉMONT C., 1980. An inbreeding sensitivity gene in Drosophila melanogaster. Experientia, 36, $169-170$.

BIÉmont C., 1983. Homeostasis, enzymatic heterozygosity and inbreeding depression in natural populations of Drosophila melanogaster. Genetica, 61, 179-189.

Biémont C.. Bouclier F., 1983. Morphological variability and concealed deleterious effects in Drosophila melanogaster populations. Experientia, 39, 313-315.

BIÉmont C., Gautier C., 1983. An inbreeding-incompatibility genetic system in Drosophila melanogaster and its frequency in natural populations. Genetica, 61, 191-195.

BouClier F., BIÉMONT C., 1982. Morphological variation and preadult viability at onegeneration inbreeding in Drosophila melanogaster : a family selection hypothesis. Genetica, 60, 13-17.

Bregliano J.C., Picard G., Bucheton A., Pelisson A., Lavige J.M., L'Heritier P., 1980. Hybrid dysgenesis in Drosophila melanogaster. Science, 207, 606-611.

Cavener D.R., Clegg M.T., 1981. Temporal stability of allozyme frequencies in a natural population of Drosophila melanogaster. Genetics, 98, 613-623.

DAVID J.R., 1982. Latitudinal variability of Drosophila melanogaster : allozyme frequencies divergence between european and afrotropical populations. Biochem. Genet., 20, 747-761.

Dobzhansky T., 1970. Genetics of the evolutionary process. Columbia University Press. New York.

Dobzhansky T., Ayala F.J., 1973. Temporal frequency changes of enzyme and chromosomal polymorphisms in natural populations of Drosophila. Proc. Natl. Acad. Sci., U.S.A., 70, 680-683.

Dubinin N.P., Tiniakov G.G., 1946. Inversion gradients and natural selection in ecological races of Drosophila funebris. Genetics, 31, 537-545.

GiLbert D.G., RICHMOND R.C., 1982. Studies of esterase 6 in Drosophila melanogaster. XII. - Evidence for temperature selection of Est 6 and Adh alleles. Genetica, 58, 109-119.

GIRARD P., 1976. Etude du polymorphisme enzymatique de 15 populations naturelles françaises de Drosophila melanogaster. Thèse de $3^{*}$ cycle. Université de Paris 7.

Golubovsky M.D., 1970. Seasonal fluctuation of lethal mutations in three natural populations of Drosophila melanogaster. Genetika (U.S.S.R.), 6, 78-91.

Hiraizumi Y., Crow J.F., 1960. Heterozygous effects on viability, fertility, rate of development and longevity of Drosophila chromosomes that are lethals when homozygous. Genetics, 45, 1071-1083.

KiDWELl M.G., 1983. Intraspecific hybrid sterility. In : Genetics and Biology of Drosophila, 125-154, Academic Press, London.

LANGLEY C.H., Ito K., VoelKer R.A., 1977. Linkage disequilibrium in natural populations of Drosophila melanogaster. Seasonal variation. Genetics, 86, 447-454.

LERNER I.M., 1954. Genetic homeostasis, 134 pp., Oliver and Boyd, Edinburgh.

Levins R., 1968. Evolution in changing environments. Princeton University Press, Princeton, N.J.

LEWONTIN R.C., 1974. The genetic basis of evolutionary changes, 346 pp., Columbia University Press, New York - London.

Lr C.C., Horvitz D.G., 1953. Some methods of estimating the inbreeding coefficient. Am. J. Hum. Genet., 5, 107-117.

Minamori S., Ito K., NaKamura A., Ando Y., Shiomi H., 1973. Increasing trend in frequencies of lethal and semilethal chromosomes in a natural population of Drosophila melanogaster. Jap. J. Genet., 48, 41-51.

Minamori S., SAito Y., 1964. Local and seasonal variations of lethal frequencies in natural populations of Drosophila melanogaster. Jap. J. Genet., 38, 290-304.

MuKai T., Yamaguchi O., 1974. The genetic structure of natural populations of Drosophila melanogaster. XI. - Genetic variability in a local population. Genetics, 76, 339-366. 
Oshima C., Watanabe T.K., Choo J.K., 1971. Deleterious genes in natural summer and autumn populations of Drosophila melanogaster. Annual Report of the National Institute of Genetics (Japan), 21, 88-96.

Parsons P.A., 1983. The evolutionary biology of colonizing species. Cambridge University Press.

Pasteur G., 1974. Génétique biochimique et populations ou : pourquoi sommes-nous multipolymorphes? Mém. Soc. Zool. Fr., 37, 473-531.

Poulik M.D., 1957. Starch gel electrophoresis in a discontinuous system of buffer. Nature, $180,1477-1479$.

Prevosti A., 1955. Geographical variability in quantitative traits in populations of Drosophila subobscura. Cold Spring Harb. Symp. Quant. Biol., 20, 294-299.

SPERLICH D., JaKSCH G., KarLIK A., 1963. Recessive lethals in island and continental populations of Drosophila melanogaster. Drosophila Inf. Service, 38, 83.

Sperlich D., Karlik A., 1970. The genetic conditions in heterozygous and homozygous populations of Drosophila. I. - The fate of alien chromosomes. Genetica, 41, 265-304.

Steiner W.W.M., 1979. Genetic variation in hawaiian Drosophila. VI. - Seasonally dependent gene changes in Drosophila mimica. Evolution, 33, 543-562.

SVED J.A., 1973. Short term heritable changes affecting viability in Drosophila melanogaster. Nature, 241, 453-454.

Templeton A.R., 1980. The theory of speciation via the founder principle. Genetics, 94, 1011-1038.

Watanabe T.K., Watanabe T., Oshima C., 1976. Genetic changes in natural populations of Drosophila melanogaster. Evolution, 30, 109-118.

Wool D., Sverdlov E., 1976. Sib mating populations in an unpredictable environment : effects on components of fitness. Evolution, 30, 119-129.

Zuitin A.I., 1938. The influence of the change of the thermal regime upon the frequency of occurrence of lethal mutations in Drosophila melanogaster. C.R. (Doklady) Acad. Sci. (U.S.S.R.), 21, 53-55. 